\title{
Structural and compositional variations in aluminium alloys rapidly quenched from the melt
}

\author{
J. A. VAN DER HOEVEN, P. VAN MOURIK, E. J. MITTEMEIJER \\ Laboratory for Metallurgy, Delft University of Technology, Rotterdamseweg 137, 2628 AL Delft, \\ The Netherlands
}

Rapid quenching of aluminium alloys by meltspinning results in ribbons showing a heterogeneous solidification structure $[1,2]$. This structural heterogeneity is expected to result from local differences in cooling rate. Thus, compositional variations due to differences in solidification conditions may be expected. Therefore, the relation between the local concentration of the alloying element and the microstructure has been investigated.

Ribbons of AlSi and AlMg alloys were prepared by applying a melt-spinning technique ([3]; in the present investigation the circumferential velocity was $31.4 \mathrm{~m} \mathrm{sec}^{-1}$ ). The hypo-eutectic alloys used were prepared from $99.994 \mathrm{wt} \% \mathrm{Al}$, $99.99 \mathrm{wt} \% \mathrm{Si}$ and $99.99 \mathrm{wt} \% \mathrm{Mg}$. The thickness of the ribbons obtained varied between 40 and $80 \mu \mathrm{m}$. Cross-sections were obtained by preparation of the ribbons along their longitudinal axis. After mechanical polishing and etching in Keller and Wilcox's reagent the cross-sections were examined with a Neophot 2 (Carl Zeiss Jena) optical microscope. X-ray microanalysis was performed with an ARL electron microprobe. The content of alloying element was determined near the wheel side, near the upper side and in the centre as an average value obtained from tracks with a length of about $45 \mu \mathrm{m}$ parallel to the outer surfaces.

Cross-sections of melt-spun ribbons are shown in Fig. 1. Three regions can be distinguished.

1. A very finely grained (sometimes "featureless") zone at the wheel (chill) side.

2. A zone of columnar grains.

3. A zone of equiaxed grains at the upper side. The results of the X-ray microanalysis are gathered in Table I. It is concluded that the concentration of alloying element is highest in the centre and lowest near the upper side, whereas the concentration near the wheel side takes an intermediate value.

The results obtained suggest a close relation

T A B L E I Local alloying element concentrations in melt-spun ribbons of AlSi and AlMg alloys. Compositions given are average values, obtained from tracks with a length of about $45 \mu \mathrm{m}$ parallel to the outer surfaces. The counting statistical standard deviations are indicated. The calculated "overall" concentration equals $\frac{1}{4}$ (concentration wheel side $+2 \times$ concentration centre + concentration upper side) (trapezoidal rule)

\begin{tabular}{lcccr}
\hline $\begin{array}{l}\text { Alloy } \\
\text { system }\end{array}$ & $\begin{array}{l}\text { "Overall" } \\
\text { concentration } \\
\text { (at \%) }\end{array}$ & $\begin{array}{l}\text { Wheel side } \\
\text { concentration } \\
\text { (at \%) }\end{array}$ & $\begin{array}{l}\text { Centre } \\
\text { concentration } \\
\text { (at \%) }\end{array}$ & $\begin{array}{l}\text { Upper side } \\
\text { concentration } \\
\text { (at \%) }\end{array}$ \\
\hline AlSi & 1.14 & $1.14 \pm 0.015$ & $1.20 \pm 0.016$ & $1.01 \pm 0.016$ \\
& 1.33 & $1.31 \pm 0.013$ & $1.37 \pm 0.014$ & $1.28 \pm 0.013$ \\
& 1.30 & $1.29 \pm 0.010$ & $1.31 \pm 0.010$ & $1.29 \pm 0.010$ \\
& 2.74 & $2.74 \pm 0.014$ & $2.78 \pm 0.014$ & $2.65 \pm 0.013$ \\
& 2.78 & $2.80 \pm 0.014$ & $2.80 \pm 0.014$ & $2.73 \pm 0.014$ \\
& 5.29 & $5.33 \pm 0.027$ & $5.36 \pm 0.027$ & $5.09 \pm 0.025$ \\
AlMg & 5.23 & $5.10 \pm 0.026$ & $5.34 \pm 0.027$ & $5.13 \pm 0.026$ \\
& 2.84 & $2.84 \pm 0.015$ & $2.84 \pm 0.015$ & $2.83 \pm 0.015$ \\
& 2.32 & $2.28 \pm 0.014$ & $2.39 \pm 0.014$ & $2.21 \pm 0.013$ \\
& 2.36 & $2.36 \pm 0.014$ & $9.75 \pm 0.014$ & $2.36 \pm 0.014$ \\
& 9.64 & $9.65 \pm 0.026$ & $15.73 \pm 0.036$ & $9.41 \pm 0.026$ \\
\hline
\end{tabular}




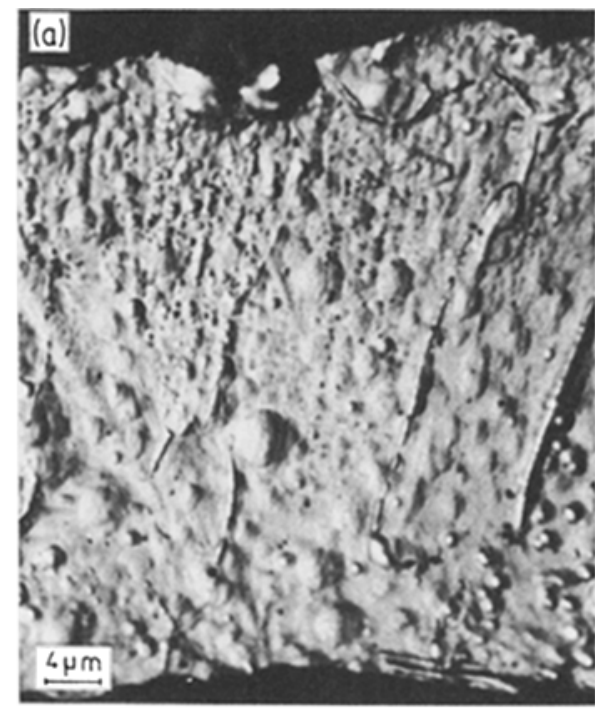

Equiaxed grains

Columnar grains

"Featureless" zone

Equiaxed grains

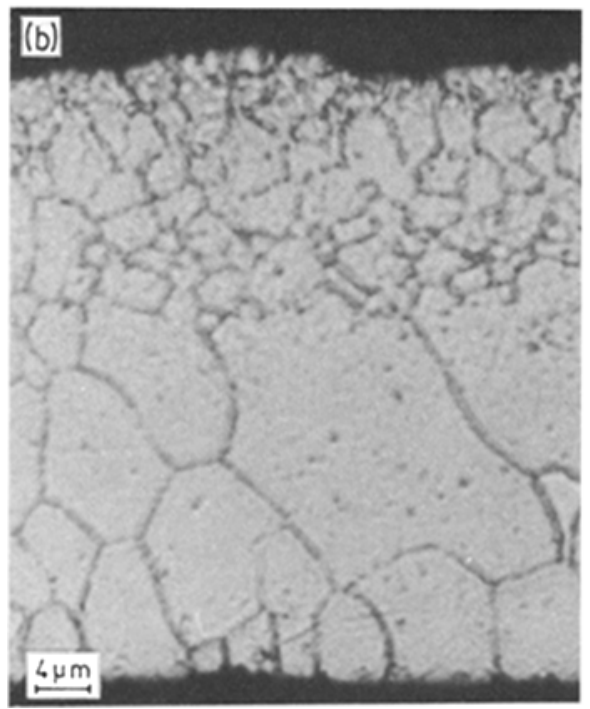

Figure 1 (a) Optical micrograph of a cross-section of a melt-spun AlSi (1.14 at \% Si) alloy. (b) Optical micrograph of a crosssection of a melt-spun AlMg (9.64 at \% Mg) alloy.
Columnar grains

Columnar grains

between solidification structure and composition. The following picture of solidification on meltspinning may explain the experimental findings.

At the wheel side the highest cooling rate and the largest undercooling are expected, yielding a very finely grained (sometimes "featureless") zone, which is thought to have solidified "diffusionless" [3]. As a consequence the alloying element concentration in this zone should equal the average alloy composition. The results in Table I support this expectation.

After solidification of the (predendritic) chill zone, the columnar (dendritic) zone will develop, accompanied by interdendritic microsegregation.
As solidification proceeds from the wheel side, solidification will start from the upper side too. Because the local cooling rate there is relatively small, equiaxed grains can develop. In this region solidification is accompanied by an appreciable solute redistribution and the solidified alloy will have a concentration of alloying element lower than the average alloy composition.

From the above discussion it follows that the ribbon centre solidifies last. Hence a marked enrichment of alloying element occurs in this region. It is suggested that solidification completes after the ribbon has lost contact with the wheel surface. 


\section{Acknowledgements}

Mr P. F. Colijn and Ing. E. J. A. van Dam afforded skillful assistance with optical microscopy and electron microprobe analysis, respectively. Dr Ir. Th. H. de Keijser and Professor B.M. Korevaar read the manuscript critically.

\section{References}

1. J. V. WOOD, P. F. MILLS, J. K. BINGHAM and
J. V. BEE, Met. Trans. A 10A (1979) 575.

2. R. DELHEZ, TH. H. de KEIJSER, E. J. MITTEMEIJER, P. van MOURIK, N. M. van der PERS, L. KATGERMAN and W. E. ZALM, J. Mater. Sci. 17 (1982) 2887.

3. A. BENDIJK, R. DELHEZ, L. KATGERMAN, TH. H. de KEIJSER, E. J. MITTEMEIJER and N. M. van der PERS, J. Mater. Sci. 15 (1980) 2803.

Received 12 November

and accepted 15 November 1982 